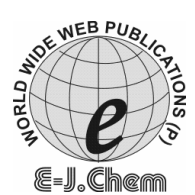

\title{
Kinetic Sorption Studies of Heavy Metal Contamination on Indian Expansive Soil
}

\author{
M. K. GUPTA*, A.K. SINGH and R. K. SRIVASTAVA ${ }^{\S}$ \\ "Department of Civil Engineering, Department of Applied Sciences, \\ Kamla Nehru Institute of Technology, Sultanpur (Uttar Pradesh)-228118, India. \\ ${ }^{\S}$ Department of Civil Engineering, Motilal Nehru National Institute of Technology, \\ Allahabad (Uttar Pradesh)- 211004, India.
}

mohitgupta0311@gmail.com

Received 28 February 2009; Accepted 4 April 2009

\begin{abstract}
Sorption of metallic cadmium from the $\mathrm{pH}$ adjusted aqueous solutions at varying initial concentrations onto an alluvial (clay) soil through batch sorption experiments was studied. The $\mathrm{pH}$ of the initial concentrations ranging between $50 \mathrm{mg} / \mathrm{L}$ to $250 \mathrm{mg} / \mathrm{L}$ was varied from 3.0 to 8.0. The sorption experiments were carried out for different durations and up to 16 hours. The cadmium continued to sorb till the last experimental $\mathrm{pH}=8$. The experimental sorption data fitted very well with both Langmuir and Freundlich isotherm models and Freundlich model gave higher correlation coefficients. The pseudosecond order kinetics model was most agreeable with the experimental sorption data, whereas the pseudo-first order model was found to be insufficient.
\end{abstract}

Keywords: Heavy metals, Metals toxicity, Sorption, Isotherms, Kinetic models.

\section{Introduction}

Heavy metals are defined as metals and metalloids generally considered being of sufficient distribution and abundance as to be in some way environmentally or biologically significant as a toxic substance ${ }^{1}$. The toxicity of a metal, as of any other substance, depends on a number of factors, such as (a) physical state (b) nature of its compound (c) mode of its entry into the human body and (d) susceptibility of the exposure. It is very difficult to demarcate toxic metals from essential ones. In fact, any metal could become toxic if ingested in sufficiently large amounts. However, it is possible to sort out those metals, which are not beneficial and at the same time show severe toxicity even at a very low concentration, e.g., cadmium, lead, chromium, metabolic nickel etc. Hence a toxic metal is the one which is neither essential nor beneficial but exhibits a positive catastrophic effect on normal function 
even when present even in small amounts, and may, at times, be responsible for permanent disorders or malfunctioning of organ system leading finally to death.

The fate and transport of a metal in soil and groundwater depends significantly on the chemical form and specification of the metal ${ }^{2}$. The mobility of the metals in ground water system is hindered by reactions that cause metals to adsorb or precipitate or chemistry that tends to keep metals associated with the solid phase and prevents them from dissolving. This mechanism can retard the movement of metals and also provide a long term source of metal contaminants ${ }^{3}$. While the various metals undergo similar reactions in a number of aspects, the extant and nature of these reactions vary under particular conditions. The solubility of the metal in soil is influenced by the chemistry of the soil and groundwater ${ }^{4}$. Factors such as $\mathrm{pH}$, Eh, ion exchange capacity, and complexation /chelation with organic matter directly affect metal solubility.

Cadmium is a rare soft metal that occurs in the natural environment typically in association with zinc ores and, to a lesser extent, with lead and copper ores. Cadmium pollution in soils ${ }^{5}$ includes phosphatic fertilizers; the mining of cadmium and smelting; atmospheric pollution from metallurgic industries; the disposal of waste containing cadmium; and urban/industrial pollution ${ }^{6}$. Cadmium can be bound in soil by simple electrostatic forces or intimately associated with metal oxides, carbonates, and organic matter. It is also found that the $\mathrm{Cd}$ solubility increases as $\mathrm{pH}$ decreases ${ }^{7,8}$. A number of investigations have shown $\mathrm{Cd}$ solubility to be dependent also on the cation-exchange capacity (CEC), clay content, organic matter, and other metal ions present ${ }^{7-10}$. The environmental fate and health effects of cadmium and its compounds have been reviewed extensively in literature ${ }^{11,12}$. For nonsmokers, ingestion of food is the largest source of cadmium exposure (about 94\%) with the rest coming from air. Acute high level exposure to cadmium by inhalation or oral routes can be fatal, including gastrointestinal, liver, and other organ damage; tracheobronchitis, pneumonitis, pulmonary endema, and long term impairment of lung functions. Renal accumulation of cadmium may result in irreversible impairment in the reabsorption capacity of renal tubules. Cadmium can alter genetic materials particularly chromosomes in mammalian cells, can inhibit repair of DNA and thereby enhancing their genotoxicity. Inorganic cadmium compounds have been classified as carcinogenic by the inhalation route ${ }^{15}$.

\section{Experimental}

The soil sample for the experimental work was collected from non-vegetation depth through an open excavation and index properties were determined as per the relevant parts of IS 2720. The soil on the basis of index properties and relevant BIS code (IS 1498: 1970) was classified as $\mathrm{CH}$. Standard stock solutions of cadmium metal (analytical reagent-grade) in deionized water were separately prepared from which $50 \mathrm{mg} / \mathrm{L}, 100 \mathrm{mg} / \mathrm{L}, 150 \mathrm{mg} / \mathrm{L}$, $200 \mathrm{mg} / \mathrm{L}$ and $250 \mathrm{mg} / \mathrm{L}$ concentrations were used for sorption experiments. The sorption experiments were performed in a rotary shaker at $15-20 \mathrm{rpm}$ for different time intervals ranging from 15 minutes to 16 hours using $300 \mathrm{~mL}$ stop corked bottles containing $250 \mathrm{~mL}$ of cadmium solution and $10 \mathrm{~g} / \mathrm{L}$ of soil. The initial $\mathrm{pH}$ of the sorbate (metal solution) was adjusted for each set of experiment by adding $0.1 \mathrm{M} \mathrm{HCl}$ or $0.1 \mathrm{M} \mathrm{NaOH}$. The partly desorbed sorbate corresponding to each time interval was centrifuged for at least 5 minutes at $500 \mathrm{rpm}$ and then vacuum-filtered to separate out the soil particles. The filtrate was used to determine the residual metal using an atomic absorption spectrophotometer (Model: Perkin Elmer 3100). The amount of metal sorbed by the soil was calculated from the initial metal concentration of the solution and metal content of the supernatant after the specified period of shaking using the following equation ${ }^{13}$ : 


$$
Q=\left(C_{o}-C_{e}\right) * \frac{V}{M}
$$

Where, $\mathrm{Q}$ is the metal uptake or sorption $(\mathrm{mg} / \mathrm{g})$ for the specified period, $\mathrm{C}_{\mathrm{o}}$ and $\mathrm{C}_{\mathrm{e}}$ are the initial and equilibrium metal concentrations in the solution $(\mathrm{mg} / \mathrm{L})$ respectively. $\mathrm{V}$ and $\mathrm{M}$ respectively are the volume of aqueous metal solution $(250 \mathrm{~mL})$ and mass of sorbent $(10 \mathrm{~g} / \mathrm{L})$.

\section{Results and Discussion}

Composition and the relevant soil properties are presented in Table 1. Langmuir and Freundlich constants at different sorbate-pH have been given in the Table 2, whereas in Table 3 kinetic parameters for different initial sorbate concentrations have been presented.

Table 1. Composition and relevant properties of soil used.

\begin{tabular}{lr}
\hline Property & Value \\
\hline Specific gravity & 2.64 \\
Particle size analysis & \\
Sand, \% & 3.3 \\
Silt, \% & 70.0 \\
Clay, \% & 26.7 \\
Atterberg's Limits & \\
Liquid limit, \% & 60.5 \\
Plastic limit, \% & 27.4 \\
Plasticity index & 33.1 \\
Shrinkage limit, \% & 11.8 \\
IS classification & $\mathrm{CH}$ \\
Chemical properties & \\
pH & 7.80 \\
Organic matter, \% & 2.25 \\
Cation exchange capacity, meq/100 g & 17.38 \\
\hline
\end{tabular}

Table 2. Langmuir and Freundlich constants at different soprbate $\mathrm{pH}$

\begin{tabular}{ccccccc}
\hline $\mathrm{pH}$ & \multicolumn{3}{c}{ Langmuir Parameters } & \multicolumn{3}{c}{ Freundlich Parameters } \\
\cline { 2 - 7 } & $\mathrm{X}_{\mathrm{m}}(\mathrm{mg} / \mathrm{g})$ & $\mathrm{K}(\mathrm{L} / \mathrm{mg})$ & $\mathrm{R}^{2}$ & $1 / \mathrm{n}$ & $\mathrm{K}_{\mathrm{f}}$ & $\mathrm{R}^{2}$ \\
\hline 3.0 & 19.72 & 0.00536 & 0.99940 & 0.73 & 0.23 & 0.99802 \\
4.0 & 23.27 & 0.00645 & 0.95021 & 0.72 & 0.32 & 0.98917 \\
5.0 & 26.94 & 0.00843 & 0.96485 & 0.70 & 0.53 & 0.99923 \\
6.0 & 28.51 & 0.01354 & 0.99652 & 0.64 & 0.93 & 0.98945 \\
7.0 & 31.35 & 0.02811 & 0.99048 & 0.65 & 1.51 & 0.98937 \\
8.0 & 33.61 & 0.04169 & 0.98099 & 0.66 & 2.04 & 0.97687 \\
\hline
\end{tabular}

Table 3. Kinetic Parameters for the effect of initial sorbate concentration.

\begin{tabular}{ccccccc}
\hline $\begin{array}{c}\text { Initial conc, } \\
\mathrm{mg} / \mathrm{L}\end{array}$ & \multicolumn{3}{c}{ First order kinetics } & \multicolumn{3}{c}{ Second order kinetics } \\
\cline { 2 - 7 } & $\begin{array}{c}\mathrm{Q}_{\mathrm{e}} \\
\mathrm{mg} / \mathrm{g}\end{array}$ & $\mathrm{k}_{1}$ & $\mathrm{R}^{2}$ & $\mathrm{Q}_{\mathrm{e}}$ & $\mathrm{k}_{2}$ & $\mathrm{R}^{2}$ \\
\hline 50 & 1.36 & 0.00640 & 0.71924 & 4.64 & 0.02799 & 0.99982 \\
100 & 2.95 & 0.00697 & 0.75058 & 9.11 & 0.01352 & 0.99986 \\
150 & 4.45 & 0.00583 & 0.073644 & 13.45 & 0.00935 & 0.99988 \\
200 & 7.15 & 0.00672 & 0.83315 & 17.86 & 0.00487 & 0.999700 \\
250 & 8.81 & 0.00691 & 0.86778 & 21.04 & 0.00386 & 0.99968 \\
\hline
\end{tabular}




\section{Effect of $p H$}

The initial $\mathrm{pH}$ of the solution is a very important factor for metal sorption on soils. The $\mathrm{pH}$, either directly or indirectly, affects several mechanisms of metal retention by soils. An important aspect of the effect of $\mathrm{pH}$ on metal mobility is the buffering capacity of soils for acidity. Many researchers have acknowledged that the adsorption of metals is directly proportional to the soil $\mathrm{pH}$. Table 4 presents sorption of cadmium between various $\mathrm{pH}$ ranges at different initial concentrations of the metal. The effect of $\mathrm{pH}$ on the sorption of cadmium on soil is illustrated in Figure 1 through a relationship between $\mathrm{C}_{\mathrm{e}}$ (sorbate remaining in solution at equilibrium conditions) and $\mathrm{Q}_{\mathrm{e}}$ (sorption of sorbate at equilibrium conditions).

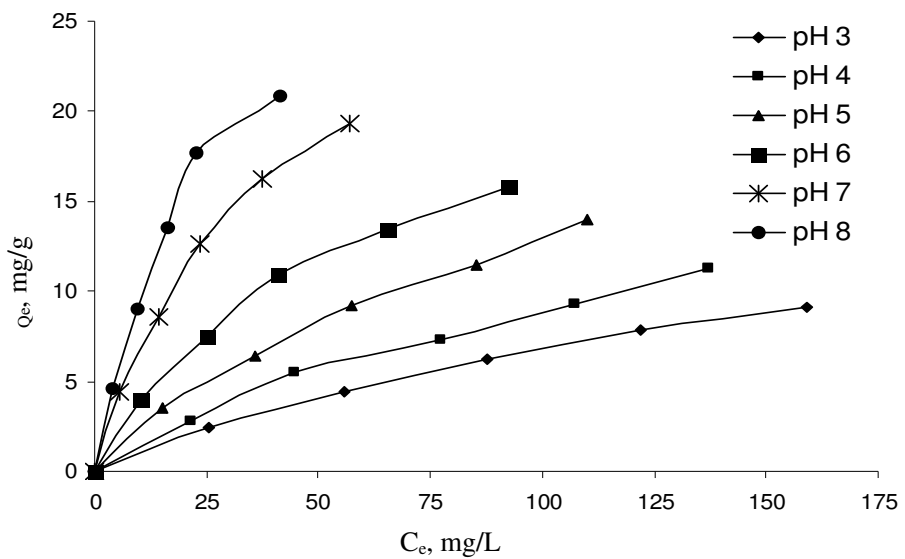

Figure 1. Effect of initial $\mathrm{pH}$ on Cd uptake by soil.

In the Table 4, effects of both the initial $\mathrm{pH}$ and initial solute concentration are seen on the sorption of $\mathrm{Cd}$. An adsorption edge starts right at the first experimental $\mathrm{pH}$ of 3 and continues up to $\mathrm{pH} 5$.

Table 4. Sorption (\%) between pH Ranges at different initial concentrations.

\begin{tabular}{cccccc}
\hline & \multicolumn{5}{c}{ Sorption, \% } \\
\cline { 2 - 6 } Initial Concentration & \multicolumn{5}{c}{ Initial pH range } \\
\cline { 2 - 6 } $\mathrm{mg} / \mathrm{L}$ & $3-4$ & $4-5$ & $5-6$ & $6-7$ & $7-8$ \\
\hline 50 & 16.4 & 22.9 & 13.7 & 11.8 & 4.0 \\
100 & 24.6 & 15.8 & 16.9 & 14.4 & 6.0 \\
150 & 16.5 & 27.0 & 17.7 & 16.0 & 7.5 \\
200 & 18.9 & 23.2 & 17.6 & 20.6 & 9.0 \\
250 & 23.8 & 24.0 & 12.6 & 22.3 & 8.1 \\
\hline
\end{tabular}

The second sorption edge is seen between $\mathrm{pH} 6$ and 7 for higher initial concentrations. Between $\mathrm{pH} 7$ and $\mathrm{pH} 8$ the sorption declines considerably, although the effect of initial concentration is quite visible. Figure 1 illustrates the comparison of sorption at different $\mathrm{pH}$ ranges shown in Table 4 . Relatively small $\mathrm{Cd}$ sorption took place at the initial $\mathrm{pH} 3$, increased little at $\mathrm{pH} 4$ and then picked up momentum at $\mathrm{pH} 5$ and 6. The sorption at initial $\mathrm{pH} 7$ was quite strong and at $\mathrm{pH} 8$ dropped substantially. The removal of $\mathrm{Cd}$ from the solution continued to increase for the maximum experimental initial $\mathrm{pH}$ of 8 . Lesser metal uptake at low $\mathrm{pH}$ values indicates that the excess of protons compete for the same binding sites on the soil particle surfaces. Previous studies ${ }^{14,15}$ reveal that the $\mathrm{pH}$ dependence of 
adsorption reactions of cationic metals is attributed partly to the preferential adsorption of hydrolysed metal species to the free metal ion. The result trends were similar to a large extent with the earlier findings reported ${ }^{16}$ that the sorption of $\mathrm{Cd}(\mathrm{II})$ on kaolinite clay increased with $\mathrm{pH}$ in both single and multi-element sorption systems. The study, for sorption of $\mathrm{Cd}(\mathrm{II})$ as a single element system, reports two adsorption stages involving adsorption edges, the first between $\mathrm{pH} 4$ and 6 , at which more than $50 \%$ of the $\mathrm{Cd}$ was absorbed and the second edge commencing at $\mathrm{pH} 6.5$ and continuing up to $\mathrm{pH} 10$, wherein $95 \%$ of the $\mathrm{Cd}$ is reported to have been sorbed. Sorption studies ${ }^{17}$ on $\mathrm{Cd}$ and $\mathrm{Pb}$ at varying $\mathrm{pH}$ on tropical coastal clay have reported that the sorption of $\mathrm{Cd}$ may be complete only at $\mathrm{pH}>8$.

\section{Langmuir and Freundlich models}

The Langmuir sorption model was chosen for the estimation of maximum sorption by the sorbent. The Langmuir adsorption isotherm can be expressed ${ }^{18}$ as:

$$
Q_{e}=\frac{X_{m} K C_{e}}{\left(1+K C_{e}\right)}
$$

Where, $Q_{e}$ is amount of metal sorbed at equilibrium per unit weight of the sorbent $(\mathrm{mg} / \mathrm{g}), \mathrm{X}_{\mathrm{m}}$, is the maximum sorption or metal uptake from solution $(\mathrm{mg} / \mathrm{g})$ and $\mathrm{K}$, is the Langmuir equilibrium constant $(\mathrm{L} / \mathrm{mg})$. For fitting the experimental data the Langmuir equation can be linearized as follows:

$$
\frac{C_{e}}{Q_{e}}=\frac{1}{X_{m} K}+\frac{C_{e}}{X_{m}}
$$

The Freundlich model is represented by the following equation ${ }^{18}$ :

$$
Q_{e}=K_{f} C_{e}^{1 / n}
$$

Where, $\mathrm{K}_{\mathrm{f}}(\mathrm{L} / \mathrm{g})$ and $\mathrm{n}$, are Freundlich constants. For fitting the experimental data, the Freundlich model can be linearized as follows:

$$
\ln Q_{\mathrm{e}}=\ln K_{f}+1 / n \ln C_{e}
$$

The Langmuir and Freundlich constants were found through linearization of experimental sorption data, and are presented in Table 2. The linearized plots of Langmuir and Freundlich models are shown in Figures $2 \& 3$. The results reveal that the model parameters are largely dependent on the initial sorbate concentration values. Langmuir sorption model served to estimate the maximum metal adsorption values where they could not be reached in batch equilibrium experiments. Both the maximum metal adsorption, $\mathrm{X}_{\mathrm{m}}$ and the Langmuir equilibrium constant, $\mathrm{K}$ increased with increasing $\mathrm{pH}$ values.

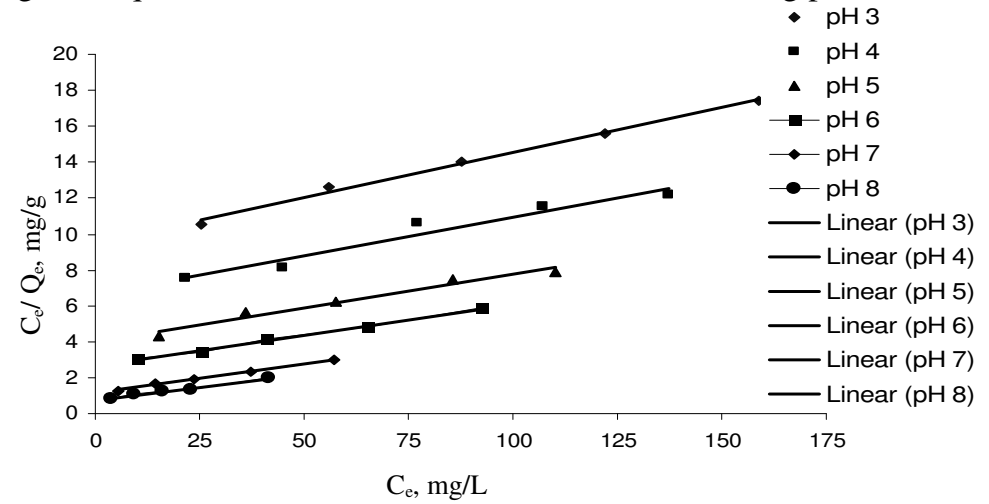

Figure 2. Linearized Langmuir isotherms at different solution $\mathrm{pH}$ values. 


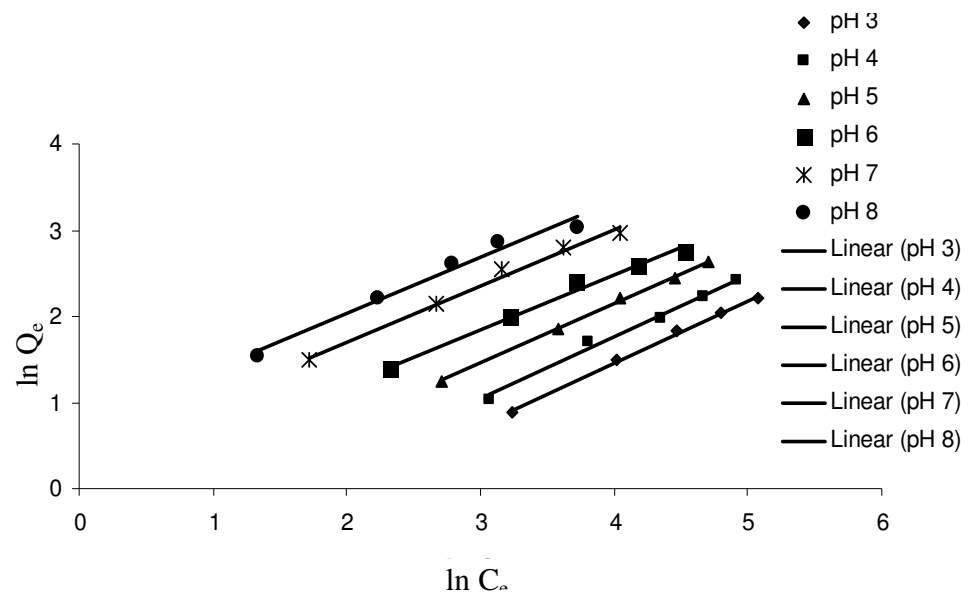

Figure 3. Linearized Freundlich isotherms at different solution $\mathrm{pH}$ values.

The Maximum sorption $\mathrm{X}_{\mathrm{m}}$ increased by nearly $70 \%$ from initial $\mathrm{pH}=3$ to the last experimental initial $\mathrm{pH}=8$. The constant $\mathrm{K}$, which represents the affinity between the sorbate and the sorbent was seen to increase continuously in the experimental $\mathrm{pH}$ range. There was a substantial increase in binding constant $\mathrm{K}$ between $\mathrm{pH}=6$ and 8 , denoting that this $\mathrm{pH}$ range was particularly favourable for sorption for $\mathrm{Cd}$ to the experimental soil. The Freundlich sorption intensity parameter $1 / \mathrm{n}$ continued to decrease right from experimental initial $\mathrm{pH}=3$ up to the last $\mathrm{pH}=8$, implying that the sorption intensity of the soil for $\mathrm{Cd}$ continued to increase up to the last experimental $\mathrm{pH}$. It was also obvious that between $\mathrm{pH} 5$ and 6 there was a sorption edge, which continued up to $\mathrm{pH}=8$. The Freundlich constant $\mathrm{K}_{\mathrm{f}}$ also continued to increase from the first initial $\mathrm{pH}$ up to the last, registering a eruption after $\mathrm{pH}=5$, which suggested that the higher $\mathrm{pH}$ values were more amenable to Cd sorption for the soil. The correlation coefficients $\mathrm{R}^{2}$, which were very high and close to unity for both the Langmuir and Freundlich models (Freundlich model gave higher coefficients for all $\mathrm{pH}$ values) together with other parameters, confirmed that the sorption of $\mathrm{Cd}$ followed Langmuir and Freundlich adsorption models.

\section{Kinetic models}

The batch sorption data was analysed using pseudo-first and second kinetics models.

\section{Pseudo-first-order model}

The linearized form of pseudo-first-order equation is given by the following expression ${ }^{19}$ :

$$
\log \left(Q_{e}-Q_{t}\right)=\log Q_{e}-K_{1} . t / 2.303
$$

Where, $Q_{t}$ is the amount of metal sorbed at any time $t(\mathrm{mg} / \mathrm{g})$ and $K_{1}$ is the rate constant $(1 / \mathrm{min})$. In order to obtain the rate constants, the plots of $\log \left(\mathrm{Q}_{\mathrm{e}}-\mathrm{Q}_{\mathrm{t}}\right)$ against $\mathrm{t}$, were made at different initial metal concentrations and are shown in Figure 4.

The kinetic constants and equilibrium adsorption $\mathrm{Q}_{\mathrm{e}}$ values from the linearized plots are given in Table 3. The calculated $\mathrm{Q}_{\mathrm{e}}$ values from the intercept of the plots were much less than the experimental $Q_{e}$ values, showing the insufficiency of first-order kinetics to fit the experimental data. Moreover, the first-order equation did not fit well for the range of contact time used in the experimental work and was valid only over the initial 30 minutes to an hour of the sorption process. The correlation coefficients $\mathrm{R}^{2}$ were also found to be rather smaller suggesting the inadequacy of the first-order kinetics. The expression ${ }^{19}$ for linearized form of pseudo-second- order kinetics is given as: 


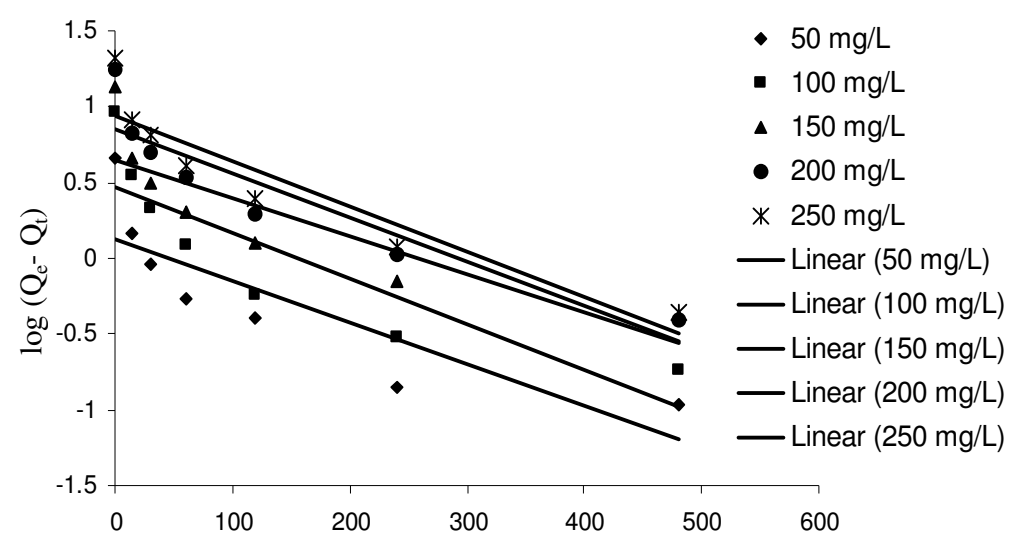

Agitation period, $\min$

Figure 4. Pseudo-first order kinetics plot at different solute concentrations and for $\mathrm{pH}=8$.

$$
t / Q_{t}=1 / K_{2} Q_{e}{ }^{2} . t
$$

In the above equation $\mathrm{K}_{2}$ is the equilibrium rate constant $\left(\mathrm{g} / \mathrm{mg} \mathrm{min}^{-1}\right)$. The plots of second-order kinetics drawn for $\mathrm{t} / \mathrm{Q}_{\mathrm{t}}$ against $\mathrm{t}$ are shown in Figure 5, whereas in the Table 3 the rate constants and the initial and equilibrium sorption values are given.

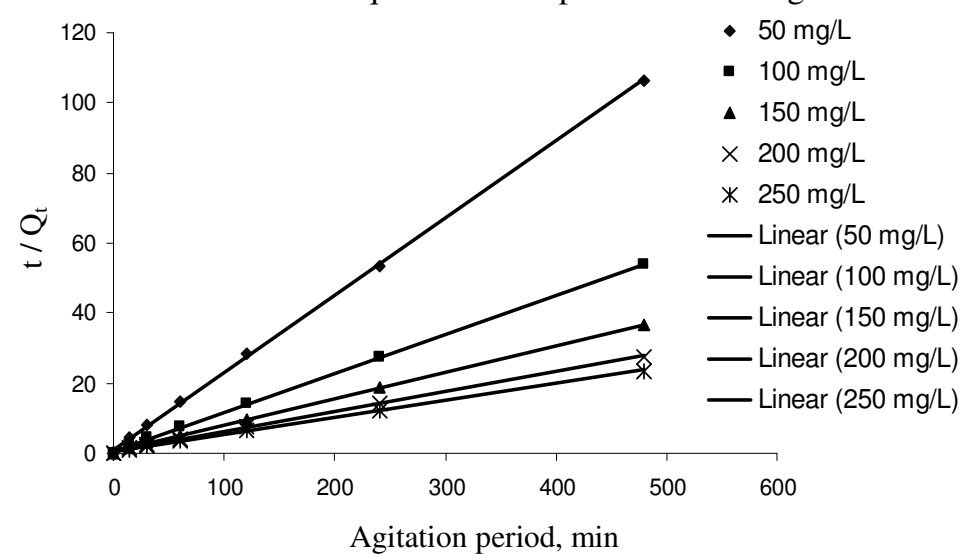

Figure 5. Pseudo-second order kinetics plot at different initial solute concentrations and for $\mathrm{pH}=8$.

Good fits were obtained for all the initial concentrations. The equilibrium adsorption $Q_{e}$ values obtained from the plots were close to the experimental values. The correlation coefficients were very near to one, the highest value being equal to 0.99990 . All the facts suggested that the experimental sorption data approximated the second-order kinetic model very well.

\section{Conclusions}

- Near equilibrium conditions were attained within 4 hours in all sorption experiments for all the initial concentrations of metal solution.

- Extraction of cadmium from the solution was found to be dependent both on the initial $\mathrm{pH}$ and the initial solute concentration.

- Both of the Langmuir and Freundlich models responded very well to the experimental sorption data, however, Freundlich model regression gave higher correlation coefficients. 
- The Langmuir model gave the value of maximum sorption $\left(X_{m}\right)$ of $33.61 \mathrm{mg} / \mathrm{g}$, which is very close to the experimental value. Thus the use of Langmuir model is validated.

- The first-order kinetics model was found to be inadequate in explaining the experimental sorption data, while the pseudo-second order model was very much agreeable with the experimental sorption values.

\section{References}

1. Lester I N, Heavy Metals in Wastewater and Sludge Treatment Processes; CRC Press Inc.: Boca Raton, FL, U.S.A, 1987, 1-40.

2 Allen J P and Torres I G, Physical Separation Techniques for Contaminated Sediments, In Recent Developments in Separation Science; Li, N. N. Ed.; CRC Press, West Palm Beach, FL; 1991, Vol. V.

3 National Research Council, Alternatives of Ground Water Cleanup, NRC; National Academy Press: Washington D. C, 1994, 336.

$4 \quad$ Evans L, J Environ Sci Technol., 1989, 23(9), 1046-1056.

5 Alloway B J, Heavy Metals in Soils, John Wiley \& Sons, New York, 1995, 368.

$6 \quad$ Nriagu J O, Environment 1990, 32, 7-33.

7 Christensen T H, Water Air Soil Pollut., 1989, 44, 71-82.

8 Chlopecka A, Bacon J R, Wilson M J and Kay J, J Environ Qual., 1996, 25, 69-79.

9 Wilkins B J and Loch J P G, Water Air Soil Pollut., 1997, 96, 1-16.

10 McBride M B, Sauve S and Hendershot W, Eur J Soil Sci., 1997, 48, 337-346.

11 ATSDR (Agency for Toxic Substance and Disease Registry), Toxicological Profile of Cadmium; U.S. Department of Health and Human Services, CAS\# 7440-43-9, 2008, 271.

12 CEPA (Canada Environmental Protection Act), Priority Substances List Assessment Report: Cadmium and its Compounds; Environment Canada and Health Canada, 1994, 97.

13 Chu K H and Hashim M A, Acta Biotechnol., 2001, 21, 295-306.

14 Cavallaro N and McBride M B, Soil Sci Soc Am J., 1980, 44, 729-732.

15 Davis J A and Leckie J O, Environ Sci Technol., 1978, 12, 1309-1315.

16 Srivastava P, Singh B and Angove M J, Competitive Adsorption of Cadmium (II) onto Kaolinite as Affected by $\mathrm{pH}$, Supersoil 2004, $3^{\text {rd }}$ Australian New Zealand Soils Conference, Dec. 5-9, 2004.

17 Lim T-T, Tay J-H and Teh C I, J Environ Qual., 2002, 31, 806-812.

18 Casey T J, Unit Treatment Processes in Water and Wastewater Engineering; John Wiley \& Sons Ltd., England, 1997, 292.

19 Ho Y S and McKay G, Trans IChem E, 1998, 76(B), 332-340. 


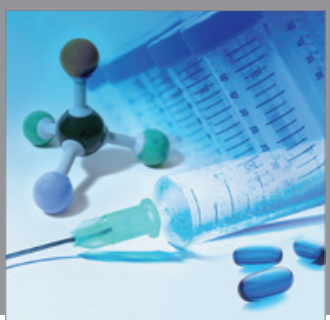

International Journal of

Medicinal Chemistry

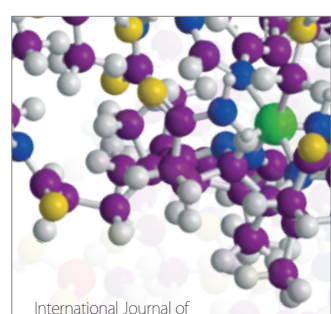

Carbohydrate Chemistry

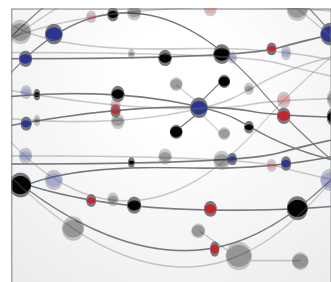

The Scientific World Journal
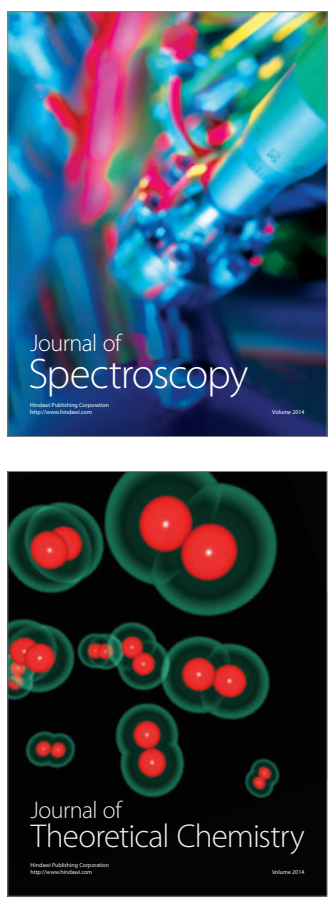
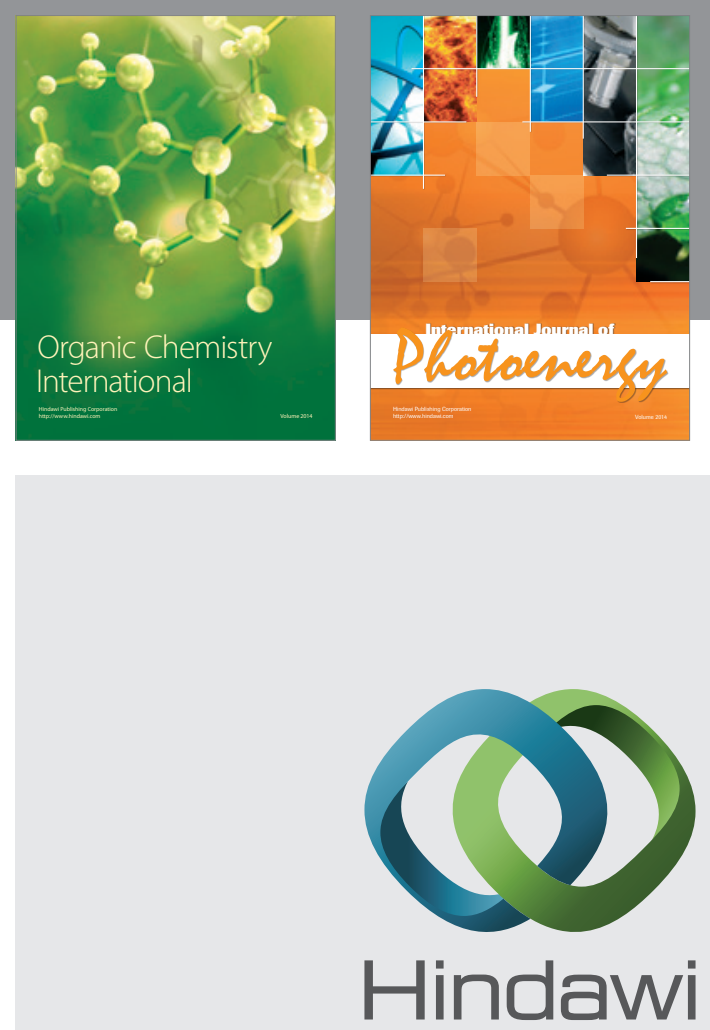

Submit your manuscripts at

http://www.hindawi.com
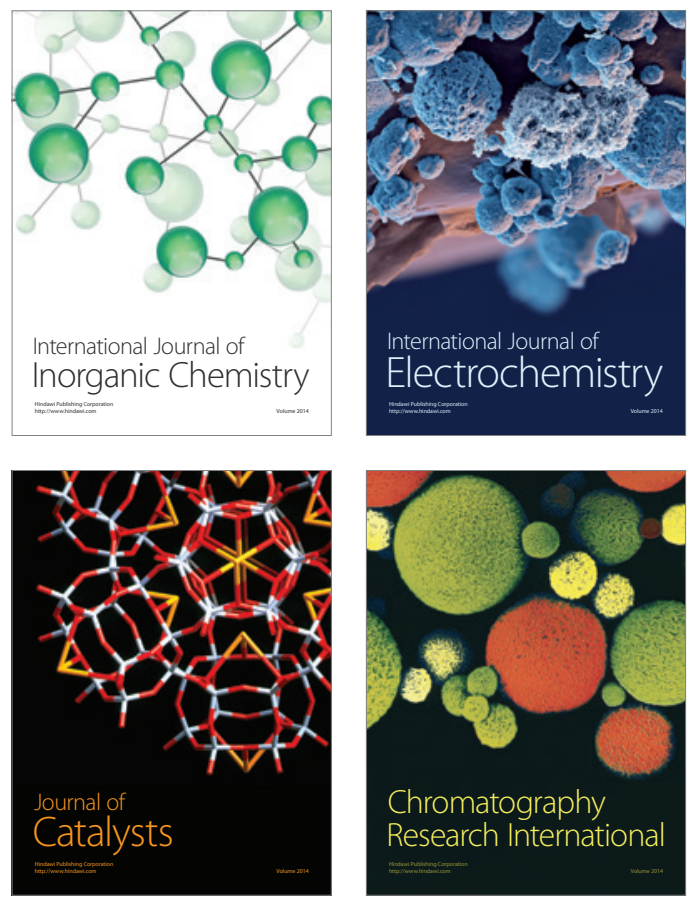
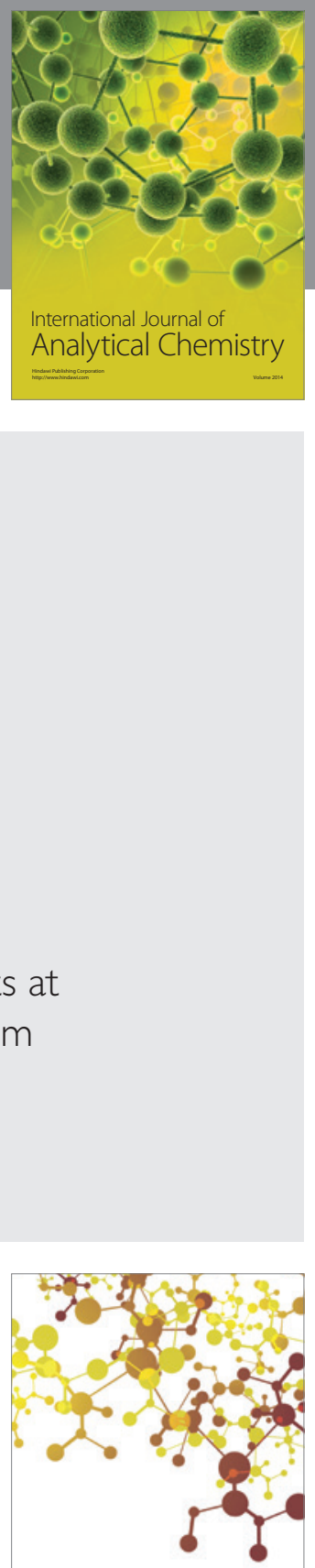

Journal of

Applied Chemistry
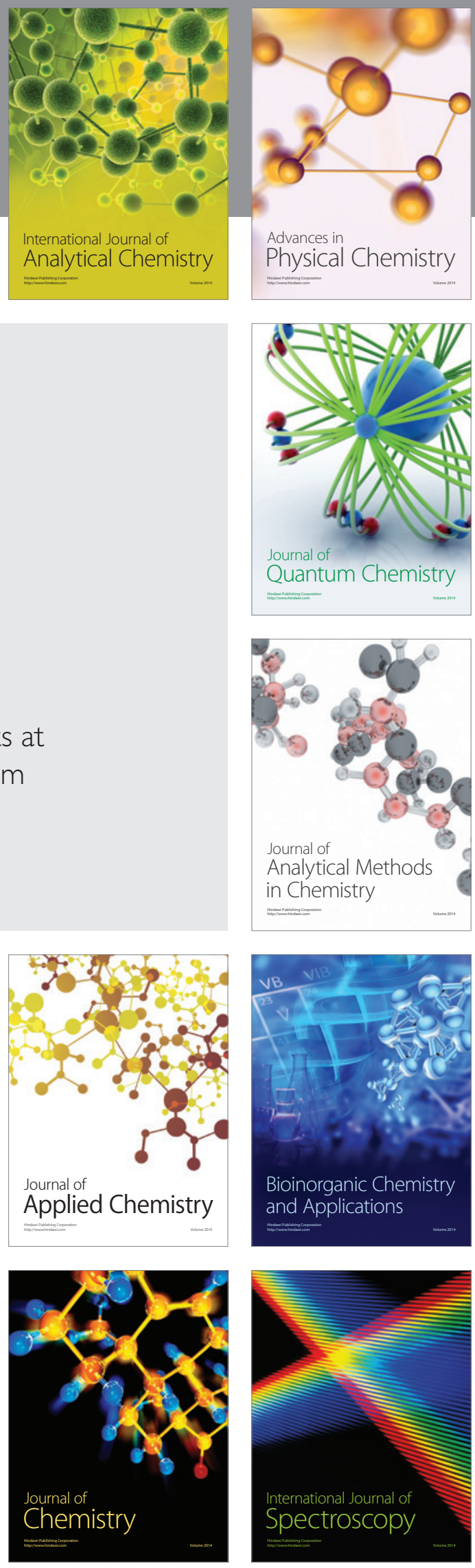